\title{
A INVENÇÃO COTIDIANA DA PESQUISA E DE SEUS MÉTODOS
}

\author{
InÊS BARBosa DE OliveIRA \\ Paulo SGarbi ${ }^{* *}$
}

$7 \begin{aligned} & \text { invenção do cotidiano é uma obra de Michel de Certeau que vem } \\ & \text { acompanhando uma imensa quantidade de pesquisadores envolvi- } \\ & \text { dos com o estudo das lógicas que movem os fazeres cotidianos, ou }\end{aligned}$ a lógica dos saberes tecidos nos cotidianos ou por eles acionados. É nesta obra que foi inspirado o título desse dossiê, bem como o desta apresentação, e não por acaso. Nesse livro, o autor vai desenvolver idéias que vêm norteando muito do que se tem produzido na área de educação por pesquisadores preocupados em superar a mesmice do que vem sendo produzido a partir dos referenciais do cientificismo moderno, sobretudo sobre as escolas e aquilo que nelas se passa, cotidianamente. É o próprio Certeau (1994, p. 81) quem alerta para a insuficiência do método.

O inconveniente do método, condição de seu sucesso, é extrair os documentos de seu contexto "histórico" e eliminar as "operaçôes" dos locutores em circunstâncias particulares de tempo, de lugar e competiçâao. É necessário que se apaguem as práticas lingüísticas cotidianas (e o espaço de suas táticas), para que as práticas científicas sejam exercidas no seu campo próprio.

Buscando uma alternativa para o desenvolvimento de um outro conhecimento da escola e das práticas cotidianas daqueles que nela atuam, esses pesquisadores vêm traçando um outro caminho: o da análise das "práticas microbianas, singulares e plurais", entendendo ser necessário

* Professora adjunta da Faculdade de Educação e do Programa de Pós-Graduação da Universidade do Estado do Rio de Janeiro (UERJ) e membro do GT "Currículo" da ANPED (coordenadora no biênio 2004-2005). E-mail: inesbo@terra.com.br

** Doutor em Educação e professor da Universidade do Estado do Rio de Janeiro - UERJ. E-mail: paulosgarbi@yahoo.com.br. 
(...) seguir o pulular desses procedimentos que, muito longe de ser controlados ou eliminados pela administração panóptica, se reforçaram em uma proliferação ilegitimada, desenvolvidos e insinuados nas redes de vigilância, combinados segundo táticas ilegíveis, mas estáveis a tal ponto que constituem regulaçôes cotidianas e criatividades sub-reptícias que se ocultam somente graças aos dispositivos e aos discursos, hoje atravancados, da organização observadora. (idem, p. 175)

Esse dossiê busca recuperar a importância dessas práticas, apresentando um pouco daquilo que vem sendo produzido nesse processo de (re)invenção do ato de pesquisar, associado às discussões acadêmicas e políticas que vêm questionando o cientificismo positivista, entendendoo como fruto da crescente consciência da insuficiência dos métodos quantitativos - voltados para as generalizações e a definição de modelos - para a compreensão da complexa dinâmica que envolve a vida cotidiana dentro e fora das escolas.

Considerando, como evidencia o texto de minha autoria presente neste volume, ${ }^{1}$ a indissociabilidade entre o desenvolvimento epistemológico da própria noção de cotidiano e as pesquisas que nele e sobre ele se desenvolvem, e, ainda, com Boaventura de Sousa Santos (1987), que em lugar de nos voltarmos para a quantificação e para as generalizações que esse procedimento parece permitir, precisamos nos dedicar a encontrar experiências exemplares que possam ser multiplicadas, trazemos para este dossiê alguns textos mais voltados para a reflexão teórico-epistemológico-metodológica sobre o cotidiano e os possíveis métodos de pesquisa que o seu estudo requer e produz, bem como outros textos que buscam apresentar saberes tecidos a partir de pesquisas concretas nos/dos/com os cotidianos desenvolvidas pelos autores.

$\mathrm{Na}$ crítica ao modelo de racionalidade que preside a ciência moderna e que se tornou, ao longo da História, um modelo global de racionalidade científica que se distingue e se defende tanto do senso comum como das humanidades, Santos (ibid.) aponta esse modelo como totalitário, na medida em que nega a racionalidade de outros modos de conhecer, assumindo-se como a única forma de conhecimento verdadeiro. $\mathrm{O}$ que interessa para esta apresentação é o fato de que essa nova visão de mundo e da vida desconfia sistematicamente das evidências da experiência imediata, as quais, estando na base do conhecimento vulgar, passam a ser tidas como ilusórias.

Ou seja, a quantificação e sua ciência derivada, a estatística, acompanhadas da necessidade de generalização que encontra na idéia de uni- 
versalidade a sua mais perfeita expressão, procuraram banir do mundo das idéias os aspectos singulares e qualitativos do real, não-controláveis por meio dos estudos que buscam regularidades que possam ser retraduzidas em "leis". Isso porque, na modernidade cientificista: “(...) o rigor científico afere-se pelo rigor das medições. As qualidades intrínsecas do objeto são, por assim dizer, desqualificadas e em seu lugar passam a imperar as quantidades em que eventualmente se podem traduzir. $O$ que não é quantificável é cientificamente irrelevante" (Santos, 2000, p. 63).

Assim, a vida cotidiana passou a ser tratada apenas nos seus aspectos quantitativos, abandonando-se, a partir daí, as especificidades das formas de se praticarem as atividades, na medida em que considera os "dados relevantes", para efeitos estatísticos, apenas as regularidades e permanências. E os danos causados às possibilidades de compreensão da riqueza da vida cotidiana surgem daí, visto que este rigor científico-matemático "(...) ao quantificar, desqualifica (...), ao objetivar os fenómenos, os objectualiza e os degrada, e, ao caracterizar os fenómenos, os caricaturiza. (...) Desta forma, o conhecimento ganha em rigor o que perde em riqueza" (idem, ibid., p. 73).

Se esse questionamento dirigido às ciências naturais já é significativo e coloca exigências novas à produção científica, quando o remetemos às ciências sociais, teremos que esse modo de tecer conhecimento desqualifica, caricaturiza, torna estúpida (ou automática) e destrói a "personalidade" da prática social investigada. Ou seja, o rigor científico de inspiração matemática e quantitativa retira das práticas sociais toda sua riqueza e politicidade, visto ser a intencionalidade política de impossível quantificação.

$\mathrm{Na}$ busca de superação deste e de outros limites do conhecimento produzido a partir desse paradigma, os estudos do cotidiano vêm-se associando à idéia, também desenvolvida por Boaventura (Santos, 1987), de que o conhecimento pós-moderno ${ }^{2}$ é local, na medida em que se organiza em torno de temas estruturados em função de sua adoção por grupos sociais concretos, como projetos de vida locais. Mas, sendo local, é também total porque salienta a exemplaridade dos projetos cognitivos locais. Ou seja, incentiva conceitos e teorias desenvolvidos localmente a emigrarem para outros lugares cognitivos, de modo a poderem ser utilizados fora do seu contexto de origem (idem, ibid., p. 48). Isso é possível porque este é um conhecimento que concebe por intermédio da imaginação (e não da operacionalização) e se generaliza por meio da qualidade e da exemplaridade (e não da quantidade). 
A partir dessa idéia, torna-se possível pensar a prática educativa concreta considerando e revalorizando a imaginação criativa de professores e alunos e dos seus fazeres, hoje marginalizados porque locais, reconhecendo neles possibilidades de aceitação ampliada e multiplicação, em virtude de algumas de suas características qualitativas.

A última parte da argumentação em torno desse aspecto da ciência pós-moderna é fundamental para se pensarem questões relacionadas à pesquisa e à apresentação de seus resultados em ciências sociais e, portanto, em educação. $\mathrm{O}$ autor assume, nessa passagem do texto, o caráter relativamente imetódico desse tipo de conhecimento, que se constitui a partir de uma pluralidade metodológica que, reconhece ele, só é possível mediante transgressão metodológica. E completa:

A transgressão metodológica repercute-se nos estilos e gêneros literários que presidem à escrita científica. A ciência pós-moderna não segue um estilo unidimensional, facilmente identificável: o seu estilo é uma configuração de estilos construída segundo o critério e a imaginação pessoal do cientista. A tolerância discursiva é o outro lado da pluralidade metodológica. (Santos, 1987, p. 49)

Um dos objetivos da organização deste dossiê se relaciona, precisamente, com essa pluralidade metodológica tornada possível nessa nova perspectiva epistemológica e com as diferentes construçóes estilísticas que dela derivam. Em contrapartida, ao reunir textos que expressam essa pluralidade sob a idéia de uma reinvenção do ato de pesquisar, tecida a partir e por intermédio das aprendizagens nos/dos/com os cotidianos, busca-se, também, reverter a idéia de que o pesquisador aprende sobre o cotidiano, no singular de acordo com esta idéia, apreendendo-lhe as características, para substituí-la pela idéia de que deles/neles/com eles, no plural, aprendemos nossas formas de pesquisar. Finalmente, penso ser de suma importância perceber que, ao contrário do que pode parecer a alguns desatentos, essa concepção de conhecimento e de pesquisa não abdica da intervenção social, apenas tenta torná-la mais realista, redefinindo o campo epistemológico do cotidiano, de modo que se encontrem nele não a mesmice e os equívocos para formular regras e modelos do que ele deveria ser, mas para compreendê-lo como arma (Pais, 2003), para uma melhor aproximação da realidade complexa e, com isso, poder contribuir para que as iniciativas emancipatórias que nele habitam e se desenvolvem possam se tornar exemplares (Santos, 1987). 
Quanto aos textos propriamente, o primeiro deles é, antes de mais nada, para mim, uma grande honra. José Machado Pais é, hoje, um sociólogo do cotidiano de grande destaque e reconhecimento. Sua obra tem nos acompanhado e a outros pesquisadores da área da educação pelo tanto que traz de reflexões significativas para o pensamento que busca recuperar e evidenciar as potencialidades transformadoras do cotidiano e das práticas criativas que nele se desenvolvem. Especificamente no texto que integra este volume, Pais desenvolve uma reflexão bem-humorada e instigante a respeito das questóes que envolvem a idéia da crescente reflexividade característica da sociedade contemporânea. Entendendo a reflexividade como indicador do poder crescente dos atores sociais com relação às estruturas sociais - decorrente do fim do peso de algumas tradiçôes -, o autor vai atribuir ao cotidiano a qualidade de espaço/tempo no qual a reflexividade impositiva que caracteriza os comportamentos reativos de correspondência às expectativas apriorísticas pode ceder espaço ao exercício da reflexividade transformadora. Considera, para isso, o cotidiano um terreno, por excelência, de reflexividades e, mais precisamente, que os poderes da reflexividade transformadora nele estão enraizados.

Ainda no contexto do pensamento que desenvolve a respeito do cotidiano, Pais aponta, a partir de Ulrich Beck, os riscos de que os efeitos perversos da modernidade reflexiva dêem origem a um cotidiano "culturalmente cego". Neste caso, o cotidiano, ele próprio, correria o risco de se enredar nas teias da alienação, fonte de cegueira dessa normalização do cotidiano, traduzida numa compulsão à repetição. Pais, contudo, não crê na inevitabilidade da "cegueira cultural" do cotidiano, exatamente porque o considera o lócus de enraizamento da reflexividade transformadora.

Penso que, não por acaso, apesar da inexistência de uma qualquer interação mais efetiva entre o trabalho de estudo epistemológico que realizo no meu cotidiano acadêmico e o do autor, o texto que trago para este volume se refere a uma cegueira epistemológica, culturalmente desenvolvida pelos sujeitos sociais em virtude dos processos de socialização e dos saberes que nesses processos se tecem. Esta cegueira pode ser superada - desaprendida - a partir de processos cotidianos de desestabilização do já-sabido, que dariam origem tanto a novas possibilidades quanto a impossibilidades, derivadas de novas e diferentes cegueiras ou, ainda, de um impedimento à repetição. Ou seja, a partir do questionamento e da desnaturalização dos valores e saberes socialmente tecidos. Penso que essa semelhança entre os dois textos surge da necessidade, sentida por nós e 
por muitos outros pesquisadores no/do cotidiano, de buscar compreender os mecanismos reais que nos mantêm vinculados a determinados saberes e valores da modernidade para procurar superá-los, no sentido da busca de uma transformação social emancipatória. Além da efetivação dessa discussão de caráter teórico-epistemológico, o texto que apresento promove um debate também em torno da pesquisa no/do cotidiano, de seus métodos, exigências e procedimentos próprios, notadamente a respeito do recurso ao trabalho com imagens.

Em texto de caráter mais teórico do que "cotidiano", Carlos Eduardo Ferraço encaminha a discussão para uma reflexão a respeito de questóes e temas relevantes nesse modo de pesquisar, preocupado em perceber como se pode, a partir de pesquisas com os cotidianos - forma preferida do autor para referir esse universo de pesquisa -, pensar o que se passa no que tange às práticas curriculares e à formação continuada. O texto volta-se, de modo crítico e denso, para o que seria uma teoria da pesquisa com o cotidiano.

Os três textos seguintes abordam experiências concretas de pesquisa nos/dos/com os cotidianos de escolas no Rio de Janeiro. Aldo Victorio Filho apresenta algumas considerações em torno de sua vivência de professor-pesquisador no/do cotidiano de uma escola pública da rede estadual. Neste ensaio de tradução do percurso de um pesquisador aprendente, o autor brinda-nos com uma escrita poética - confirmando o que anunciava Boaventura de Sousa Santos a respeito da tolerância discursiva inerente aos novos modos de pesquisar -, ao tecer seus comentários e percepçóes, sempre originais e instigantes, a respeito daquilo que acredita não ser possível - nem desejável - fazer a partir da reflexão que lhe foi pedida sobre o seu cotidiano de professor-pesquisador, que seria aprisionar as metodologias criadas para dar conta da sua pesquisa específica em um modelo explicativo qualquer a ser generalizado e aplicado em outras circunstâncias. Entende que pesquisar o cotidiano é um processo de (re)invenção permanente do ato de pesquisar - como aliás preconizamos desde a própria escolha do título.

O texto de Regina Coeli Moura de Macedo constitui-se como uma belíssima narrativa, tecida a partir de murais, suas imagens e seus sujeitos, a respeito dos diversos contextos, circunstâncias, atores, problemas, acontecimentos etc., presentes na vida cotidiana de uma escola que atende as séries iniciais do ensino fundamental, mas que é parte de uma grande e renomada instituição pública federal de ensino. Per- 
correndo os espaços da escola - da qual também é professora - e "bisbilhotando" seus murais e aqueles que os fazem, a autora cria para si alguns entendimentos sobre esse universo de imagens que habitam o cotidiano das escolas, em sua multiplicidade de modos e de motivações. Ao entrevistar uma das professoras a respeito do assunto, ela se permite repensar suas impressões, modificar algumas, manter outras etc. O mais importante, entretanto, é a possibilidade que o texto abre para que nós, leitores, compreendamos a riqueza de saberes e fazeres que habitam essa escola, e tantas outras, evidenciando, por meio disso, a importância do desenvolvimento desse tipo de pesquisa e do uso de material imagético para a tessitura de novos saberes sobre o que se passa no cotidiano das escolas, "mesmo quando, aparentemente, nada se passa" (Pais, 2003), saberes mais "antenados". com a complexidade do real, suas nuances e delicadezas.

Numa outra direção, Alexandra Garcia, inspirada por sua experiência concreta de pesquisa de campo realizada para sua dissertação de mestrado, busca desvendar os significados epistemológico-metodológicos - entendendo-os como indissociáveis - de sua pesquisa e das pesquisas nos/dos/com os cotidianos. Servindo-se com maestria da metáfora dos múltiplos sabores encontrados nas escolas, quando nos permitimos nos despir dos modelos que "embrulham" em um idêntico e insosso celofane todas as balas, a autora vai pensar uma "epistemologia das balas sem papel”, na busca por desvendar os diferentes e criativos modos por meio dos quais a instituição escola - embrulhada no papel do modelo da escola capitalista burguesa -, no seu cotidiano, abriga múltiplas escolas, com sabores diversos e fugazes como a duração de uma bala sem papel.

A busca da autora se inscreve neste dossiê como uma tentativa de percebermos que o processo de superação/desaprendizagem da cegueira epistemológica à qual nossa formação nos levou requer esforços para ver o invisível a partir dos parâmetros definidos pelos modelos. Por outro lado, é importante assinalar que essas mudanças modificam a cegueira e os modos de sua manifestação, mas não a derrota totalmente. Ou seja, de acordo com as culturas das quais nos originamos, com as crenças e convicções que abraçamos, com os saberes que tecemos e com as vivências que experimentamos, seremos vitimados por cegueiras diferentes, que comprometem visão/leitura/escuta/sentimento de dimensões e partes diferentes do mundo, mas jamais deixaremos de ser parcialmente cegos, exatamente porque, como já nos ensinou Boaventura de Sousa Santos 
(2004), toda cultura é parcial. Daí, toda apreensão de um real qualquer será, ela também, sempre parcial. Assim, posso terminar esta apresentação defendendo a idéia de que a captura da totalidade de um real social qualquer é uma ilusão, tão impossível de ser realizada quanto perigosa de ser pretendida, como já aprendemos com a falência dos pensamentos totalizantes e totalitários que, depois de gozar de imenso prestígio científico-político-social, vêm sendo postos em questão por tantos pesquisadores. Ao trazer textos que narram teórica, epistemológica, política e metodologicamente alguns modos de pesquisar inovadores, este volume pretende ser uma pequena contribuição para o questionamento da idéia de que a pesquisa em educação pode ter uma receita qualquer que sirva para todo e qualquer objetivo.

\section{Notas}

1. "Aprendendo nos/dos/com os cotidianos a ver/ler/ouvir/sentir o mundo"

2. Adoto, aqui, a terminologia do autor, recuperando também o alerta que ele faz de que o uso do termo "pós-moderno" se vincula à impossibilidade momentânea de se cunhar uma expressão melhor.

\section{Referências bibliográficas}

CERTEAU, M. A invenção do cotidiano I: as artes do fazer. Petrópolis: Vozes, 1994.

PAIS, J.M. Vida cotidiana: enigmas e revelações. São Paulo: Cortez, 2003. SANTOS, B.S. Um discurso sobre as ciências. Porto: Edições Afrontamento, 1987.

SANTOS, B.S. A crítica da razão indolente: contra o desperdício da experiência. São Paulo: Cortez, 2000.

SANTOS, B.S. Por uma sociologia das ausências e uma sociologia das emergências. In: SAnTOS, B. (Org.). Conhecimento prudente para uma vida decente. São Paulo: Cortez 2004. p. 777-823. 